\title{
Performance Evaluation of Surface-Enhanced Raman Scattering- Polymerase Chain Reaction Sensors for Future Use in Sensitive Genetic Assays
}

Yixuan Wu, Namhyun Choi, Hao Chen, Hajun Dang, Lingxin Chen,* and Jaebum Choo*

Cite This: Anal. Chem. 2020, 92, 2628-2634

Read Online

ACCESS | Lill Metrics \& More | 回 Article Recommendations ｜ sl Supporting Information

ABSTRACT: We report a surface-enhanced Raman scattering (SERS)-based polymerase chain reaction (PCR) assay platform for the sensitive and rapid detection of a DNA marker (pagA) of Bacillus anthracis. Real-time quantitative PCR (RT-qPCR) has been recently considered a gold standard for the quantitative evaluation of a target gene, but it still suffers from the problem of a long thermocycling time. To address this issue, we developed a conceptually new SERS-PCR platform and evaluated its performance by sequentially measuring the Raman signals of $B$. anthracis DNA after the completion of different thermocycling numbers. According to our experimental data, SERSPCR has lower limits of detection (LODs) than RT-qPCR under the

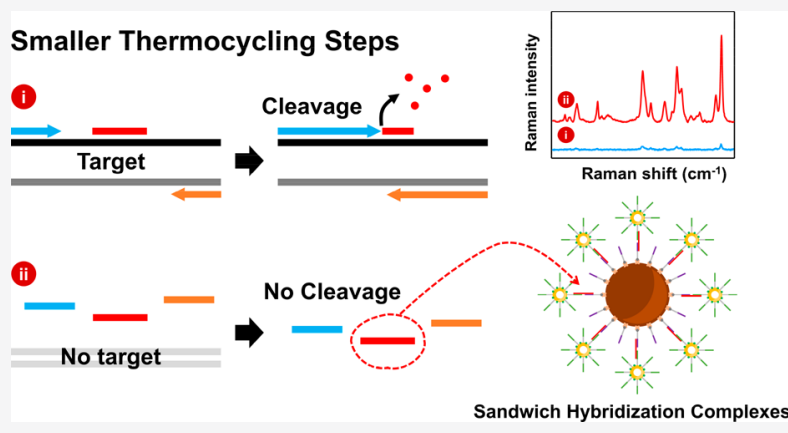
small cycle number of 20 . Particularly, it was impossible to detect a target DNA amplicon using RT-qPCR before the number of cycles reached 15, but SERS-PCR enabled DNA detection after only five cycles with an LOD value of 960 pM. In addition, the dynamic range for SERS-PCR $(0.1-1000$ pM) is wider than that for RTqPCR (150-1000 pM) under the same condition. We believe that this SERS-PCR technique has a strong potential to be a powerful tool for the rapid and sensitive diagnosis of infectious diseases in the near future.

Since its emergence in 1983, the polymerase chain reaction $\checkmark$ (PCR) technique has garnered great attention in molecular diagnostics. ${ }^{1,2}$ Herein, a low copy number of target nucleic acids can be exponentially amplified using PCR primers through repetitive thermocycling steps. These days, the quantification of a specific gene sequence is more important than the simple identification of its presence for the accurate diagnosis of genetic and infectious diseases. ${ }^{3}$ In this case, realtime quantitative PCR (RT-qPCR) is considered a gold standard for the quantitative analysis of a target gene., Scheme 1a illustrates a fundamental principle of RT-qPCR. A DNA TaqMan probe with a fluorescent dye at one end and a quencher at the opposite end is used for RT-qPCR assays. The close proximity of the quencher to the fluorescent dye prevents its fluorescence emission in its initial stage. Degradation of the probe, through the hybridization process of forward and reverse primers, allows separation between the fluorescent dye and quencher, enhancing the fluorescence emission intensity. Consequently, the increase in the fluorescence intensity is proportional to the concentration of the amplicons produced during the PCR process. Quantification of a target DNA can be determined by measuring the relative fluorescence intensity along the thermocycle number. RT-qPCR, however, suffers from a couple of major limitations. First, a long assay time is required for the quantitative evaluation of a target gene due to the long amplification process. ${ }^{6,7}$ Thirty thermocycling steps approximately are needed to acquire a desired amplification result from the low concentration of a target gene. Second, the long amplification process also causes a false-positive signal since the concentration of a target gene is lower than that of nonspecific genes in many cases. This causes the risk for incorrect identification of nonspecific genes of contaminants. ${ }^{8,9}$ If highly sensitive detection is possible even for a low concentration of a target gene with a small number of thermocycling steps, the problems of the long assay time and false-positive detection might be resolved. To this end, many different types of nanoparticle-based sensitive detection methods including colorimetric, ${ }^{10,11}$ electrochemical, ${ }^{12,13}$ and time-resolved fluorescence detection methods ${ }^{14,15}$ have been developed so far. Nonetheless, these detection methods still have a limit to surpass to acquire sufficient signal enhancement for the sensitive detection of a target gene. In this work, a surface-enhanced Raman scattering (SERS)-based PCR (SERS-PCR) technique has been developed to overcome the low-sensitivity problem inherent in conventional detection methods. When SERS nanotags are exposed to a laser light, the

Received: October 3, 2019

Accepted: January 15, 2020

Published: January 15, 2020 
Scheme 1. Schematic Illustration of the Principle of (a) RT-qPCR and (b) SERS-PCR Assays for the pagA Target Gene of B. anthracis

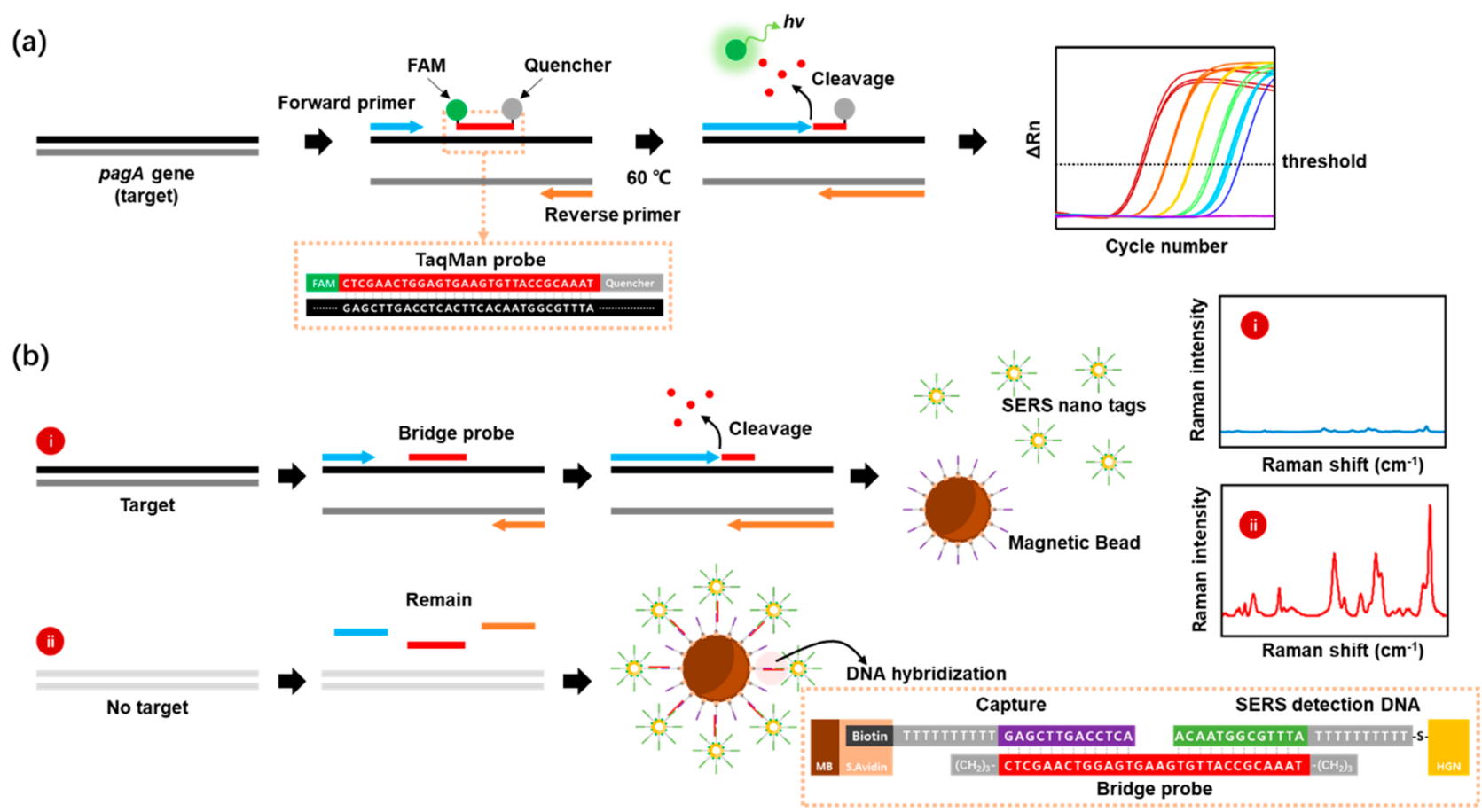

incident field is dramatically enhanced at active sites known as "hot junctions" by localized surface plasmon effects. ${ }^{16-19}$ Therefore, we believe that this highly sensitive SERS-PCR technique enables the detection of target genes with smaller thermocycling steps.

In this work, a label-free bridge probe was used as a hydrolysis agent for SERS-PCR assays (Scheme 1b). In the presence of target DNAs (i), the bridge probe was hydrolyzed into free $\operatorname{dNTP}(\mathrm{A}, \mathrm{G}, \mathrm{T}$, and $\mathrm{C}$ ) bases through the hybridization of forward and reverse primers. In the absence of target DNA (ii), however, most of the bridge probes remained in solution because hybridization of target DNA did not occur. Consequently, the concentration of the target DNA is inversely proportional to the concentration of the remaining bridge probes. For their quantitative evaluation, the SERSbased assay technique using magnetic beads has been used. $^{20-23}$ As shown in Scheme 1b, capture DNA-conjugated magnetic beads and detection DNA-conjugated hollow gold nanoparticle (HAuNP) SERS nanotags were used as supporting substrates and detection probes, respectively. Herein, capture and detection DNAs were designed to hybridize with a bridge probe in a sandwich format (the square box at the right bottom side in Scheme $1 \mathrm{~b}$ ). This magnetic bead-based assay provides several advantages compared to a two-dimensional SERS substrate-based assay. First, a three-dimensional hybridization pattern on the surface of a magnetic bead provides a dramatically increased loading density of target DNAs. Second, this technique overcomes the slow reaction problem in a two-dimensional planar surface due to the diffusion-limited kinetic process. Finally, more reproducible quantification is possible because the Raman signals can be measured for an average nanoparticle ensemble in solution. Quantitative evaluation of the bridge probe could be determined by monitoring the characteristic Raman peak intensity of SERS nanotags.
As a proof of concept, the toxic pagA of Bacillus anthracis was used as a target DNA marker to evaluate the performance of our SERS-PCR assay platform. Since the terrorist attack in September 2001, B. anthracis has been known as one of the most serious hazardous biological weapons of mass destruction. ${ }^{24}$ The pagA, the major virulence factor of $B$. anthracis, is an essential indicator in pathogenic $B$. anthracis identification. ${ }^{25}$ To date, several papers regarding the application of SERS-PCR have been reported. ${ }^{26-29}$ For instance, Wee et $\mathrm{al}^{26}$ and Li et al. ${ }^{29}$ reported multiplex SERS-PCR assay results for clinically important DNA point mutations. White et al. ${ }^{27}$ compared the analytical sensitivity and multiplexing capacity of SERS-PCR with those of fluorescence-based RT-PCR for 195 clinical samples. However, to the best of our knowledge, any systematic study on the relation between thermocycling steps and SERS detection sensitivity has not been reported yet. To address this issue, the performance of SERS-PCR was evaluated by sequentially measuring the Raman signals of $B$. anthracis DNA after the completion of different thermocycling numbers. Herein, we report the correlation between RT-qPCR and SERS-PCR to better understand the feasibility of SERSPCR for rapid and sensitive genetic analysis.

\section{EXPERIMENTAL SECTION}

Materials. Cobalt chloride hexahydrate $\left(\mathrm{CoCl}_{2} \cdot 6 \mathrm{H}_{2} \mathrm{O}\right)$, gold chloride trihydrate $\left(\mathrm{HAuCl}_{4}\right)$, sodium borohydride $\left(\mathrm{NaBH}_{4}\right)$, trisodium citrate $\left(\mathrm{Na}_{3} \mathrm{C}_{6} \mathrm{H}_{5} \mathrm{O}_{7}\right)$, tris $(2$ carboxyethyl)phosphine hydrochloride (TCEP), Tween 20, phosphate buffer (PB, $\mathrm{pH} 7.4,0.1 \mathrm{M})$, Tris- $\mathrm{HCl}$ buffer $(\mathrm{pH}$

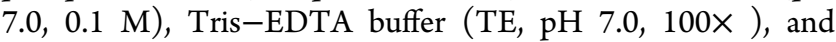
saline-sodium citrate buffer (SSC, $\mathrm{pH}$ 7.0) were purchased from Sigma-Aldrich (St. Louis, MO, U.S.A.). Malachite green isothiocyanate (MGITC) was purchased from Life Technologies (Eugene, OR, U.S.A.). Streptavidin-activated magnetic beads (Dynabeads MyOne) were purchased from Invitrogen 
(a)

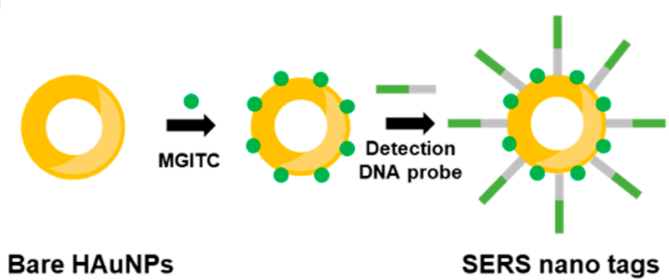

Bare HAuNPs (b)

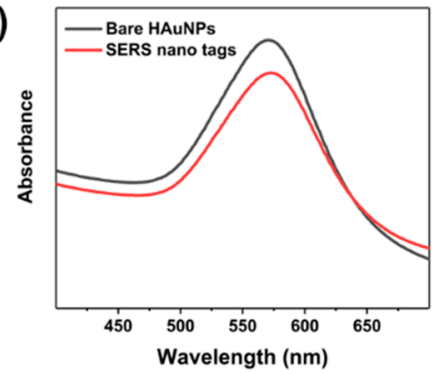

(c)

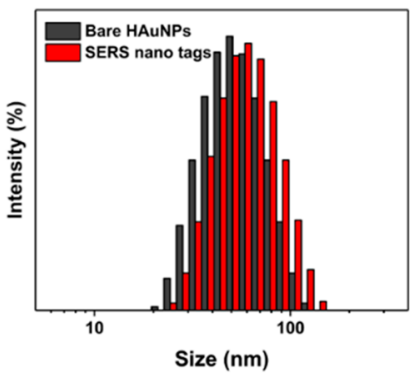

(d)
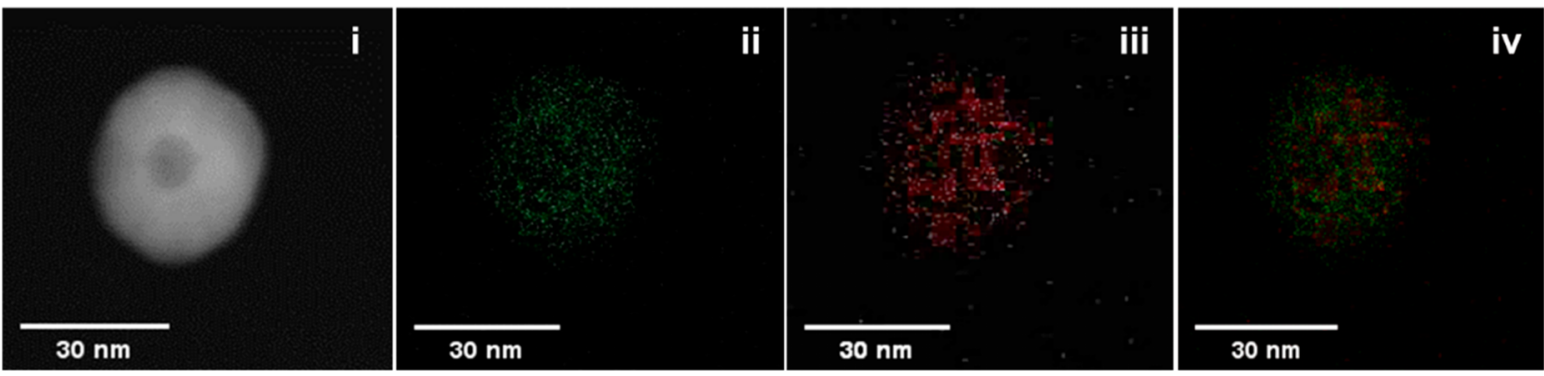

Figure 1. (a) Sequential conjugation process of Raman reporter molecules (MGITCs) and detection DNA probes on the surface of HAuNPs. (b) UV-vis absorption spectra and (c) DLS distribution data for bare HAuNPs (black) and SERS nanotags (red). (d) TEM image of SERS nanotags (i) and EDS elemental mapping images for gold (ii, green) and phosphorus (iii, orange) and their overlay image (iv).

(Beaverton, OR, U.S.A.). DNA probes and target DNA oligonucleotides were purchased from Integrated DNA Technologies, Inc. (Coralville, IA, U.S.A.). All the related nucleotides were estimated to be high-performance liquid chromatography (HPLC) purification grade, and other chemicals were analytical reagent grade. MicroAmp 96-well tray/retainer sets (4379590) and support bases (4381850) were purchased from Applied Biosystems (Foster City, CA, U.S.A.). Premix EX Taq was purchased from TaKaRa (Shuzo, Japan). All solutions were prepared with ultrapure water $(18.2$ $\mathrm{M} \Omega$ ) obtained using a Millipore Milli-Q water purification system (Billerica, MA, U.S.A.).

Instrumentation. Dynamic light scattering (DLS) data were obtained using a Nano-ZS90 apparatus (Malvern Instruments). Transmission electron microscopy (TEM) images were obtained on a JEM-1400 transmission electron microscope (JEOL, Japan). An accelerating voltage of $200 \mathrm{kV}$ was applied to gather high-magnification transmission electron microscopy (TEM) images and energy-dispersive X-ray spectroscopy (EDS) element mapping images. Real timequantitative PCR assays were performed using QuantStudio 6 and 7 Flex real-time PCR systems (Thermo Fisher Scientific, Waltham, MA, U.S.A.). All the Raman measurements were carried out using an inVia Renishaw Raman microscope system (Renishaw, New Mills, U.K.).

Preparation of Detection DNA-Conjugated SERS Nanotags. To prepare SERS nanotags, Raman reporter molecules (MGITC) and detection DNAs were sequentially immobilized on the surface of HAuNPs. ${ }^{23}$ First, $5 \mu \mathrm{L}$ of $10^{-4}$ M MGITC was added to the HAuNP solution and kept under gentle stirring at room temperature for $30 \mathrm{~min}$. Then, thiolmodified DNAs were conjugated on the surface of MGITCfunctionalized HAuNPs. Thiol-modified DNAs were produced from the DNAs in the disulfide form by the following method. First, $20 \mu \mathrm{L}$ of $10^{-5} \mathrm{M}$ disulfide DNA was mixed with $1 \mu \mathrm{L}$ of $10^{-2} \mathrm{M}$ TCEP. The mixture was incubated for $30 \mathrm{~min}$ at room temperature to produce free thiol groups via the reduction of disulfide groups. DNA conjugation reactions were performed by adding thiol-modified DNAs to MGITC-functionalized HAuNPs, and $2 \mu \mathrm{L}$ of Tween $20(10 \% \mathrm{v} / \mathrm{v})$ was subsequently added to maintain the stability of DNA-conjugated HAuNPs. This mixture was maintained overnight at $4{ }^{\circ} \mathrm{C}$, and then a 0.1 $\mathrm{M}$ PB solution ( $\mathrm{pH} 7.4$ ) was added to the mixture to maintain the $\mathrm{PB}$ concentration at $0.01 \mathrm{M}$. Subsequently, $5 \mu \mathrm{L}$ of a $5.0 \mathrm{M}$ $\mathrm{NaCl}$ buffer ( $\mathrm{pH}$ 7.4) was added and reacted overnight at room temperature to induce a salt aging process. The mixture was centrifuged at $6000 \mathrm{rpm}$ for $10 \mathrm{~min}$ to remove excess reagents. After discarding the supernatant solution, remaining DNA-conjugated SERS nanotags were stored in $1 \mathrm{~mL}$ of distilled water for further use.

Preparation of Capture DNA-Conjugated Magnetic Beads. Capture DNA was immobilized on magnetic beads through a streptavidin-biotin interaction. First, $1 \mathrm{~mL}$ of $1 \mu \mathrm{m}$ sized streptavidin-functionalized magnetic beads $(1 \mathrm{mg} / \mathrm{mL}$, $\sim 1.6 \mathrm{pM}$ ) was washed twice with $1 \times$ Tris $-\mathrm{HCl}$ binding buffer $(\mathrm{NaCl} 2 \mathrm{M}, \mathrm{pH} 7.0,0.1 \mathrm{M})$, and then resuspended in $1 \mathrm{~mL}$ of $0.5 \times$ Tris $-\mathrm{HCl}$ buffer. Next, $5 \mu \mathrm{L}$ of $10^{-4} \mathrm{M}$ biotinylated capture DNA was added into the magnetic beads and incubated for $30 \mathrm{~min}$. Capture DNA-conjugated magnetic beads were separated using a magnet, and then washed with $1 \times$ Tris $-\mathrm{HCl}$ buffer to remove unbound DNAs. Finally, the functionalized magnetic beads were stored at $1 \mathrm{~mL}$ of $1 \times \mathrm{TE}$ buffer for future use.

RT-qPCR Assays. RT-qPCR assays using TaqMan have been performed for the quantitative evaluation of target DNAs in B. anthracis. In this work, it was used as a control method for the evaluation of SERS-PCR assays, the selectivity and specificity of the primer pair already determined by previous work. ${ }^{30}$ First, $1 \mu \mathrm{L}$ of B. anthracis DNA, $12.5 \mu \mathrm{L}$ of Premix EX Taq, $500 \mathrm{nM}$ of primer pair, $100 \mathrm{nM}$ TaqMan probe, and $1 \times$ Rox reference were mixed in a PCR tube. All the experiments were run in triplicate. The amplification was carried out under the following conditions. Preheating temperatures were $52{ }^{\circ} \mathrm{C}$ for $1 \mathrm{~min}$ and $95{ }^{\circ} \mathrm{C}$ for $1 \mathrm{~min}$, respectively. Thermocycle 
temperatures and assay times were $95{ }^{\circ} \mathrm{C}$ for $15 \mathrm{~s}$ and $60{ }^{\circ} \mathrm{C}$ for $1 \mathrm{~min}$, respectively. PCR products were analyzed using the QuantStudio 6 and 7 Flex PCR instrument.

SERS-PCR Assays. In SERS-PCR assays, the label-free bridge probe, which does not contain fluorescent dye (FAM) and quencher in its $3^{\prime}$ - and 5 '-terminal positions, was used as a hydrolysis agent. After PCR amplification, $2 \mu \mathrm{L}$ of the solution was extracted from the PCR tube, and then mixed with $300 \mu \mathrm{L}$ of 200 pM SERS nanotags and $10 \mu \mathrm{L}$ of $1.6 \mathrm{pM}$ magnetic beads for the formation of DNA sandwich complexes. Then, $20 \mu \mathrm{L}$ of a $20 \times$ SSC buffer solution was added to eliminate steric interference. After a period of reaction, the magnetic sandwich complexes were separated using a magnet, and then resuspended in $1 \times \mathrm{TE}$ buffer for SERS detection. Raman signals were measured using the inVia Raman microscope system. A He-Ne laser operating at $633 \mathrm{~nm}$ was used as the excitation source with a laser power of $100 \mathrm{~mW}$. All the Raman spectra were collected for a second in the $700-1700 \mathrm{~cm}^{-1}$ range. A $20 \times$ objective lens was used to focus a laser beam on a capillary glass tube. To minimize variations in the Raman intensity from batch to batch, all the signals were normalized using the Raman intensity of a blank PCR tube.

\section{RESULTS AND DISCUSSION}

Characterization of DNA-Conjugated SERS Nanotags and Optimization of Hybridizations. Figure S1 shows the TEM images of HAuNPs synthesized by the sacrificial galvanic replacement method under different magnifications. The hollow structure of HAuNPs could be clearly identified under higher magnification TEM images (Figure S1, parts $c$ and d). Figure la shows a sequential conjugation process of Raman reporter molecules (MGITCs) and detection DNA probes on the surface of HAuNPs. To confirm whether the detection DNA was bound to the surface of HAuNPs, UV-vis spectra, DLS distributions, TEM images, and EDS element mapping images were acquired. The UV-vis absorption band for DNA-conjugated HAuNPs showed a red shift from 570 to $572 \mathrm{~nm}$ compared to that for bare HAuNPs (Figure $1 \mathrm{~b}$ ). In addition, the DLS distribution showed that the diameter of DNA-conjugated HAuNPs also increased after DNA immobilization, as shown in Figure 1c. Figure 1d shows the TEM image of SERS nanotags and EDS elemental mapping images for gold and for phosphorus. Panel iv of Figure 1d displays their overlay image. The EDS mapping image of phosphorus in panel iii of Figure 1d demonstrates that DNAs were successfully bound to the surface of SERS nanotags because the phosphorus group only exists in the backbone of DNA molecules. All the experimental data confirmed that detection DNAs were successfully bound to the surface of HAuNPs. To determine the optimal temperature and reaction time for DNA hybridization, $300 \mu \mathrm{L}$ of 200 pM SERS nanotags, $2 \mu \mathrm{L}$ of 10 nM bridge DNA probes, and $10 \mu \mathrm{L}$ of $1.6 \mathrm{pM}$ magnetic beads were mixed to react under various reaction times and temperatures. The SERS signal intensity increased gradually with the reaction time but showed a trivial change after $6 \mathrm{~min}$ as shown in Figure S2a. The reaction temperature also showed the same trend against time after $32{ }^{\circ} \mathrm{C}$ in Figure S2b. On the basis of these experimental results, the optimal reaction time and temperature were determined to be $6 \mathrm{~min}$ and $32{ }^{\circ} \mathrm{C}$, respectively. Herein, the strongest Raman peak intensity at $1614 \mathrm{~cm}^{-1}$ was used for quantitative evaluation of the sandwich magnetic DNA hybridization complexes.
Figure 2 shows the test results of SERS-PCR assays for 1 $\mathrm{nM}$ B. anthracis DNA after 20 PCR cycles. To identify the (a)

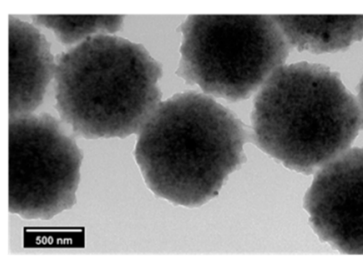

(c)

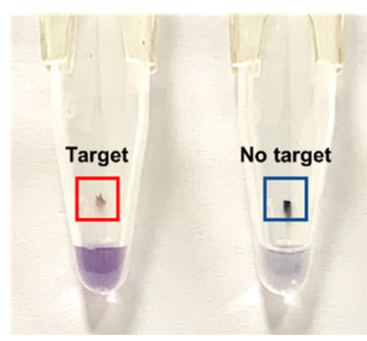

(d)

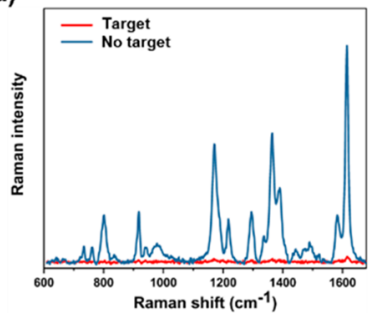

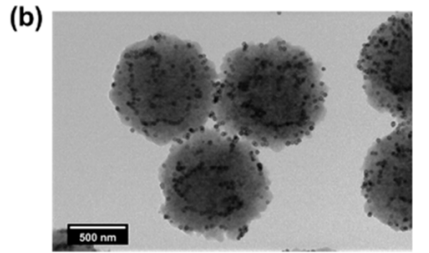

Figure 2. TEM images of magnetic DNA sandwich complexes after 20 PCR cycles in the (a) presence and (b) absence of $1 \mathrm{nM} B$. anthracis target gene. (c) Digital photographs for solutions with (left) and without (right) target genes and (d) corresponding Raman spectra.

formation of sandwich complexes, their TEM images were obtained and compared with each other (Figure 2, parts a and b). No SERS nanotag was bound onto magnetic beads in the presence of target DNAs, but many SERS nanotags were bound onto the surface of magnetic beads in the absence of target DNAs due to the formation of sandwich complexes by bridge DNA probes. These incompatible TEM images provide strong evidence of our SERS-PCR assay protocol working well. The adsorption of SERS nanotags onto the surface of magnetic beads leads to a decrease in their concentration, and consequently, the solution changed to transparent, as shown in Figure 2c. Their corresponding Raman spectra, shown in Figure $2 \mathrm{~d}$, are also consistent with the TEM images and solution color changes. In the presence of target DNAs, sandwich-type hybridization complexes could not be formed because most of the bridge DNA probes were hydrolyzed into free dNTP bases. Consequently, a relatively weak Raman peak intensity was observed in this case. On the other hand, bridge DNA probes were not hydrolyzed in the absence of target DNAs, and their Raman peak intensity increased due to the formation of sandwich DNA hybridization complexes between SERS nanotags and magnetic beads.

Quantitative Analysis of $B$. anthracis DNA Using SERS-PCR Assays. Table S1 provides information about the base sequences of target, primers, and TaqMan and bridge probes for RT-qPCR and SERS-PCR assays. To evaluate the detection sensitivity of our SERS-PCR assays, nine different concentrations of $B$. anthracis DNA ranging from 0 to $10^{3} \mathrm{pM}$ were reacted with bridge probes under the optimized temperature and reaction time conditions $\left(32{ }^{\circ} \mathrm{C}\right.$ and 6 min). After the completion of 20 thermocycles, magnetic SERS-based assays were carried out for various concentrations of PCR amplicons. As shown in Figure 3a, the relative Raman peak intensity $\left(I_{\text {sample }} / I_{\text {blank }}\right)$ at $1614 \mathrm{~cm}^{-1}$ decreased gradually with increase in the $B$. anthracis DNA concentration from $10^{-4}$ $\mathrm{pM}$ to $1.0 \mathrm{nM}$. Figure $3 \mathrm{~b}$ shows the variation in the corresponding relative Raman peak intensity. Herein, error 


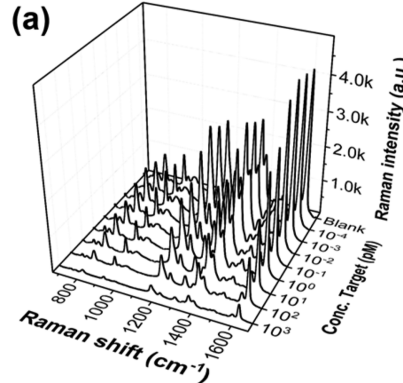

(b)

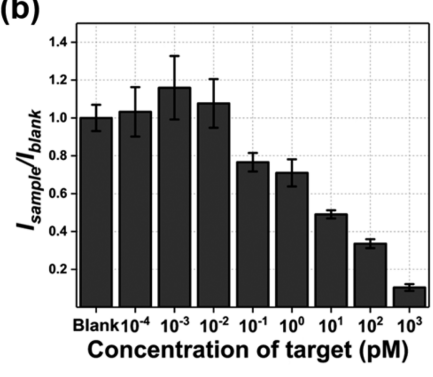

Figure 3. (a) Raman spectra and (b) relative intensity variations of Raman peak at $1614 \mathrm{~cm}^{-1}$ for nine different concentrations of $B$. anthracis target gene. Error bars indicate standard deviations calculated from three measurements.

bars represent the standard deviations from three measurements. As described above, the Raman peak intensity was inversely proportional to the concentration of the target DNA. The limit of detection (LOD) was estimated to be $1.10 \times 10^{-1}$ $\mathrm{pM}$, and the correlation coefficient was 0.987 . This low LOD indicates that SERS-PCR can reduce the assay time by measuring DNA amplicons after a small number of thermocycles.

However, it was found that the relative Raman peak intensity variations were not consistent when the concentration of the target DNA was lower than $10^{-2} \mathrm{pM}$. When the concentration of the target DNA was extremely low (below the LOD), there exists an uncertainty of the measured Raman intensity due to nonspecific binding problems or steric hindrance issues caused by other species.

Performance Comparison of SERS-PCR and RT-qPCR. Figure 4 compares the standard assay curves of RT-qPCR and (a)

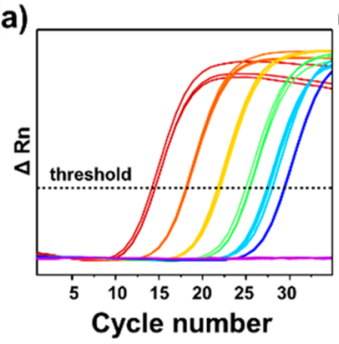

(b)

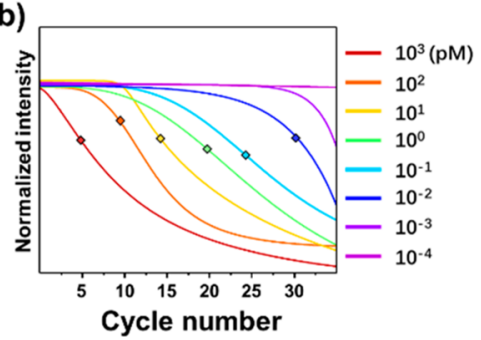

Figure 4. Comparison of standard assay curves for B. anthracis target genes between (a) RT-qPCR and (b) SERS-PCR. The minimum cycle number, required to achieve an intended target DNA concentration, can be estimated from the threshold $\mathrm{Ct}$ value. The variation of normalized Raman peak intensity along the cycle number is plotted in panel $b$, and the corresponding LOD values for given concentrations are marked in the figure. Raman peak intensity at 1614 $\mathrm{cm}^{-1}$ decreased gradually with increasing cycle number due to the cleavage of bridge probes.

SERS-PCR. In the case of RT-qPCR (Figure 4a), the fluorescence signal intensity increased with the amount of amplified target DNAs through the cleavage of TaqMan probes. Herein, the threshold cycle $(\mathrm{Ct})$ is defined as the number of the fractional cycle at which the fluorescence intensity passes through the fixed threshold. Therefore, the minimum cycle number (Figure S3), which is required to achieve an intended target DNA concentration, can be estimated from this $\mathrm{Ct}$ value. The variation in the normalized Raman peak intensity along the cycle number is plotted in
Figure $4 \mathrm{~b}$ and Figure S4, and the corresponding LOD values for given concentrations are marked in the figure. Raman peak intensity at $1614 \mathrm{~cm}^{-1}$ gradually decreased with increasing cycle number due to the cleavage of bridge probes.

The LODs for RT-qPCR and SERS-PCR with the increase in cycle number are compared in Figure 5a. Both of LODs
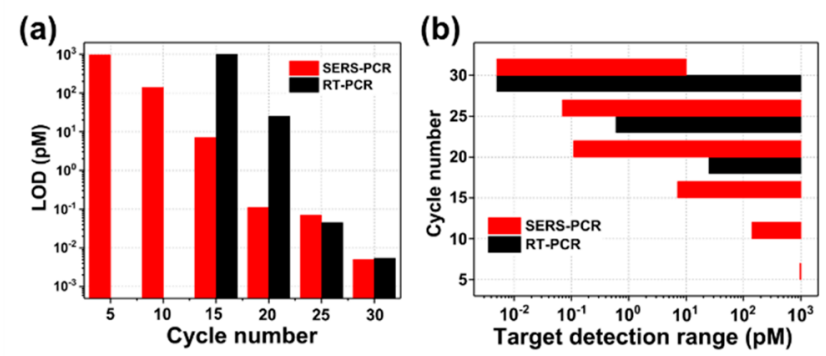

Figure 5. (a) Comparison of LODs and (b) variations of detection dynamic ranges for RT-qPCR and SERS-PCR with increasing cyclic numbers.

under different thermocycles were determined using the fourparameter sigmoidal function in Tables S2 and S3. As expected, SERS-PCR has lower LODs than RT-qPCR for all cycle numbers. It was impossible to detect a target DNA by RT-qPCR before the number of cycles reached 15 (Figure 5a). On the other hand, SERS-PCR enabled DNA detection even after five cycles with an LOD value of $960 \mathrm{pM}$. After 15 thermocycles, the LOD values for RT-qPCR and SERS-PCR were estimated to be 1000 and $71 \mathrm{pM}$, respectively. These data demonstrate that SERS-PCR shows high sensitivity compared with RT-qPCR under the low PCR cycle number of 20 . The LODs below 10 thermocycles were determined from the exponential fitting function shown in Table S2. Thus, it can be concluded that SERS detection method has shown promise in overcoming low-sensitivity problems inherent in the fluorescence detection method. When the concentration of target DNA is low, RT-qPCR could not collect enough fluorescence signals to break the threshold level.

However, it is worthy to note that RT-qPCR and SERSPCR demonstrate comparable LOD values over 25 cycles in Figure 5a. The fluorescence intensity increased gradually with the cycle number in RT-qPCR because the concentration of the fluorescent dye (FAM) increased owing to the hydrolyzation of TaqMan DNA probes. In the case of SERS-PCR, however, the Raman intensity of sandwich DNA complexes decreased gradually with the cycle number because the concentration of bridge probes decreased gradually because of their cleavage through the hybridization process of forward and reverse primers. Consequently, the concentration of the fluorescence-induced material increased but that of the SERSinduced material decreased with increasing cycle number.

Figure $5 \mathrm{~b}$ also shows variations in the detection dynamic ranges for RT-qPCR and SERS-PCR with the number of thermocycles. When the concentration of DNA amplicon was in the range of $10-1000 \mathrm{pM}$, it was possible to detect them using SERS-PCR after 5-10 cycles. However, it could not be detected by RT-qPCR below 15 cycles. When the cycle number was 20, the dynamic range of SERS-PCR (0.1-1000 $\mathrm{pM})$ was wider than that of RT-qPCR (150-1000 pM). The dynamic ranges for SERS-PCR and RT-qPCR are going to be similar when the cycle number is over 25 . On the basis of the 
experimental data, we can conclude that SERS-PCR has wider dynamic ranges for smaller cycle numbers. In particular, it is possible to detect DNA amplicons in the 10-1000 pM range using SERS-PCR, but they cannot be detected using RTqPCR under 15 cycles. Since this work focused on the feasibility of SERS-PCR under small cycle numbers, our results satisfactorily meet the demand.

In this work, a $10 \mathrm{nM}$ bridge probe was used for hydrolyzation reaction, but it was expected that the detection sensitivity would improve greatly if a lower concentration of bridge probe is used for the assay. When a $10 \mathrm{nM}$ bridge probe was used for PCR amplification, the LOD of SERS-PCR was estimated to be $140 \mathrm{pM}$ after 10 cycles. On the other hand, it was estimated to be $23.3 \mathrm{pM}$ when a $1.0 \mathrm{nM}$ bridge probe was used for PCR amplification (Figure S5a). When the concentration of bridge probes was reduced from 10 to 1.0 $\mathrm{nM}$, a relatively higher proportion of bridge probes participated in the hydrolyzation reaction and induced more sensitive Raman signal changes. The LOD of SERS-PCR was 4 orders of magnitude lower than that of RT-qPCR when the concentration of bridge probes decreased to $1.0 \mathrm{nM}$ after the completion of 15 thermocycles. On the contrary, the dynamic range for the use of $1.0 \mathrm{nM}$ bridge probes was much narrower than that for the use of $10 \mathrm{nM}$ bridge probes in the range of 525 PCR cycles (Figure S5b).

Reproducibility and Selectivity of SERS-PCR. To evaluate the reproducibility of SERS-PCR, the DNA hybridization assays for six different concentrations of $B$. anthracis DNA were tested after 20 PCR cycles. The percent coefficient variations $(\mathrm{CVs})$ were determined from the measurement data. As shown in Figure 6a, the CV values under 10 pM DNA (a)

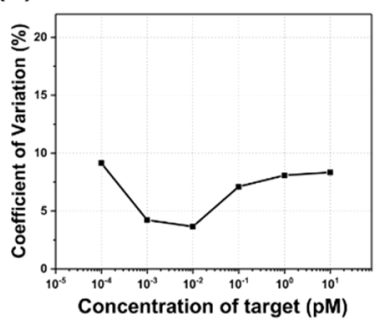

(b)

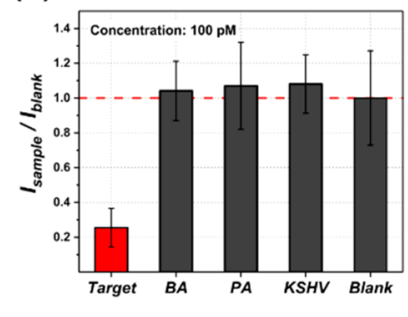

Figure 6. (a) CV (\%) variations for six different concentrations of $B$. anthracis DNA after 20 PCR thermocycles. (b) Selectivity test for same concentrations of different DNA species, Bacillary angiomatosis (BA), Pseudomonas aeruginosa (PA), and Kaposi's sarcoma-associated herpesvirus (KSAH). After 20 PCR cycles, the Raman peak intensity at $1614 \mathrm{~cm}^{-1}$ was measured, and three normalized values of Raman peak intensity were determined for four different DNA targets.

concentration show an excellent precision (less than 10\%). The tests for the same concentrations of different DNA species, B. angiomatosis (BA), P. aeruginosa (PA), and Kaposi's sarcoma-associated herpesvirus (KSAH), were also performed to evaluate the selectivity of SERS-PCR assays (Table S4). After 20 PCR cycles, the Raman peak intensity at $1614 \mathrm{~cm}^{-1}$ was estimated, and the corresponding normalized values of Raman peak intensity were determined for four different DNA targets. Histograms for the detection results are displayed in Figure $6 \mathrm{~b}$. The Raman peak intensity only decreased in the presence of target $B$. anthracis DNA. This indicates that SERS-PCR only responds to a target DNA and exhibits inherently good selectivity toward it.

\section{CONCLUSION}

Currently, RT-qPCR is regarded as a gold standard for the quantification of a gene expression level, but a major limitation still exists in terms of the long thermocycling time required. Therefore, a new technique for rapid and sensitive gene assays is still needed. To address this issue, we developed a new SERS-PCR assay platform that specifically quantifies DNA levels with superior performance over the existing RT-qPCR method. The performance of SERS-PCR was evaluated by sequentially measuring the Raman signals of the $B$. anthracis DNA marker (pagA) after the completion of different thermocycling numbers. In this work, the number of thermocycles for assay could be reduced significantly using the highly sensitive SERS detection capability. In the case of RT-qPCR, it was impossible to detect a target DNA amplicon before the number of cycles reached 15, but SERS-PCR enabled DNA amplicon detection after only five cycles with an LOD value of $960 \mathrm{pM}$. Additionally, the dynamic range for SERS-PCR $(0.1-1000 \mathrm{pM})$ is wider than that for RT-qPCR (150-1000 pM) under the same condition. Due to the high sensitivity of SERS-PCR, it has a strong potential to be a powerful tool in the rapid and sensitive diagnosis of infectious diseases. Furthermore, amplification-free detection of genetic diseases might be possible if a more sensitive SERS platform for target gene detection is developed in the near future.

\section{ASSOCIATED CONTENT}

\section{Supporting Information}

The Supporting Information is available free of charge at https://pubs.acs.org/doi/10.1021/acs.analchem.9b04522.

Method for the preparation of hollow gold nanoparticles (HAuNPs), TEM images of HAuNPs, optimization of temperature and reaction time for the formation of sandwich complexes, comparison of LODs and dynamic ranges for different concentrations of bridge probe, and additional tables for base sequences, LOD fitting functions, and DNA base sequences for the selectivity test (PDF)

\section{AUTHOR INFORMATION}

\section{Corresponding Authors}

Lingxin Chen - Key Laboratory of Coastal Environmental Processes and Ecological Remediation, Yantai Institute of Coastal Zone Research, Chinese Academy of Sciences, Yantai 264003, China; 이이이.org/0000-0002-3764-3515; Email: lxchen@yic.ac.cn

Jaebum Choo - Department of Chemistry, Chung-Ang

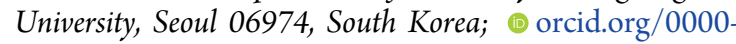
0003-3864-6459; Email: jbchoo@cau.ac.kr

\section{Authors}

Yixuan Wu - Department of Chemistry, Chung-Ang University, Seoul 06974, South Korea

Namhyun Choi - Department of Bionano Technology, Hanyang University, Ansan 15588, South Korea

Hao Chen - Department of Chemistry, Chung-Ang University, Seoul 06974, South Korea

Hajun Dang - Department of Chemistry, Chung-Ang University, Seoul 06974, South Korea

Complete contact information is available at:

https://pubs.acs.org/10.1021/acs.analchem.9b04522 


\section{Author Contributions}

Y.W. and N.C. contributed equally to this work. J.C. and L.C. designed and supervised the research, N.C. performed the synthesis and characterization of HAuNPs and SERS nanotags, Y.W., H.D., and H.C. conducted the SERS-PCR and RTqPCR assays for $B$. anthracis DNA marker (pagA) after the completion of different thermocycling numbers, and Y.W., L.C., and J.C. contributed to writing the manuscript. All the authors discussed and approved the manuscript.

\section{Notes}

The authors declare no competing financial interest.

\section{ACKNOWLEDGMENTS}

The National Research Foundation of Korea supported this work (Grant No. 2019R1A2C3004375). This research was also supported by the Chung-Ang University research scholarship grants in 2019.

\section{REFERENCES}

(1) Donnelly, P. Nature 2008, 456, 728-731.

(2) Tsai, S. Q.; Iafrate, A. J.; Joung, J. K. Nat. Med. 2014, 20, 1103.

(3) Hsiang, J.-C.; Jablonski, A. E.; Dickson, R. M. Acc. Chem. Res. 2014, 47, 1545-1554.

(4) Giulietti, A.; Overbergh, L.; Valckx, D.; Decallonne, B.; Bouillon, R.; Mathieu, C. Methods 2001, 25, 386-401.

(5) Grosdidier, M.; Aguayo, J.; Marçais, B.; Ioos, R. Plant Pathol. 2017, 66, 359-367.

(6) Niemz, A.; Ferguson, T. M.; Boyle, D. S. Trends Biotechnol. 2011, $29,240-250$.

(7) Thomson, D. A. C.; Tee, E. H. L.; Tran, N. T. D.; Monteiro, M. J.; Cooper, M. A. Biomacromolecules 2012, 13, 1981-1989.

(8) Adamski, M. G.; Gumann, P.; Baird, A. E. PLoS One 2014, 9, e103917.

(9) Chen, L.; Lee, S.; Lee, M.; Lim, C.; Choo, J.; Park, J. Y.; Lee, S.; Joo, S.-W.; Lee, K.-H.; Choi, Y.-W. Biosens. Bioelectron. 2008, 23, $1878-1882$

(10) Lam, M. K.; Gadzikwa, T.; Nguyen, T.; Kausar, A.; AlladinMustan, B. S.; Sikder, M. D.; Gibbs-Davis, J. M. Langmuir 2016, 32, $1585-1590$.

(11) Mao, X.; Liu, S.; Yang, C.; Liu, F.; Wang, K.; Chen, G. Anal. Chim. Acta 2016, 909, 101-108.

(12) Sun, Y.; Ren, Q.; Liu, B.; Qin, Y.; Zhao, S. Biosens. Bioelectron. 2016, 78, 7-13.

(13) Wang, Y.; Jiang, L.; Leng, Q.; Wu, Y.; He, X.; Wang, K. Biosens. Bioelectron. 2016, 77, 914-920.

(14) Jin, Z.; Geißler, D.; Qiu, X.; Wegner, K. D.; Hildebrandt, N. A. Angew. Chem., Int. Ed. 2015, 54, 10024-10029.

(15) Mayr, R.; Haider, M.; Thünauer, R.; Haselgrübler, T.; Schütz, G. J.; Sonnleitner, A.; Hesse, J. Biosens. Bioelectron. 2016, 78, 1-6.

(16) Vendrell, M.; Maiti, K. K.; Dhaliwal, K.; Chang, Y. T. Trends Biotechnol. 2013, 31, 249-257.

(17) Hu, S.; Liu, B. J.; Feng, J. M.; Zong, C.; Lin, K. Q.; Wang, X.; Wu, D. Y.; Ren, B. J. Am. Chem. Soc. 2018, 140, 13680-13686.

(18) Kradolfer, S.; Lipiec, E.; Baldacchini, C.; Bizzarri, A. R.; Cannistraro, S.; Zenobi, R. ACS Nano 2017, 11, 12824-12831.

(19) Yang, S.; Dai, X.; Stogin, B. B.; Wong, T. S. Proc. Natl. Acad. Sci. U. S. A. 2016, 113, 268-273.

(20) Gao, R.; Cheng, Z.; Wang, X.; Yu, L.; Guo, Z.; Zhao, Z.; Choo, J. Biosens. Bioelectron. 2018, 119, 126-133.

(21) Chon, H.; Lee, S.; Yoon, S.-Y.; Chang, S.-I.; Lim, D. W.; Choo, J. Chem. Commun. 2011, 47, 12515-12517.

(22) Yoon, J.; Choi, N.; Ko, J.; Kim, K.; Lee, S.; Choo, J. Biosens. Bioelectron. 2013, 47, 62-67.

(23) Cheng, Z.; Choi, N.; Wang, R.; Lee, S.; Moon, K. C.; Yoon, S. Y.; Chen, L.; Choo, J. ACS Nano 2017, 11, 4926-4933.

(24) Spencer, R. C. J. Clin. Pathol. 2003, 56, 182-188.
(25) Bartkus, J. M.; Leppla, S. H. Infect. Immun. 1989, 57, 22952301.

(26) Wee, E. J.; Wang, Y.; Tsao, S. C.; Trau, M. Theranostics 2016, 6, $1506-1513$.

(27) White, P. L.; Hibbitts, S. J.; Perry, M. D.; Green, J.; Stirling, E.; Woodford, L.; McNay, G.; Stevenson, R.; Barnes, R. A. J. Clin. Microbiol. 2014, 52, 3536-3543.

(28) Restaino, S. M.; White, I. M. Lab Chip 2018, 18, 832-839.

(29) Li, X.; Yang, T.; Li, C. S.; Song, Y.; Lou, H.; Guan, D.; Jin, L. Theranostics 2018, 8, 1678-1689.

(30) Ellerbrok, H.; Nattermann, H.; Ozel, M.; Beutin, L.; Appel, B.; Pauli, G. FEMS Microbiol. Lett. 2002, 214, 51-59. 